\title{
Half Mode Substrate Integrated Waveguide Leaky Wave Antenna with Broadside Gain Enhancement for Ku-Band Applications
}

\author{
Rahul AGRAWAL, Pravesh BELWAL, Suresh GUPTA \\ Dept. of ECE, DIT University, Mussorrie Diversion road, 248009 Dehradun, India \\ rahul1@dituniversity.edu.in, \{pravesh, suresh.chandra.gupta\}@dituniversity.edu.in
}

Submitted January 22, 2019 / Accepted June 7, 2019

\begin{abstract}
A miniaturized frequency scanned leaky wave antenna (LWA) based on half mode substrate integrated waveguide (HMSIW) with open stop-band suppression is proposed. The modified cross-slot is etched on the top of $H M S I W$ as the radiating element. The folded and unfolded ground plane designs of the proposed HMSIW LWA are compared and analyzed with respect to their Bloch impedance characteristics and it is found that further miniaturization and gain improvement at broadside by $\sim 2 \mathrm{dBi}$ are achieved for folded ground plane design. The proposed LWA scans a region from $-40^{\circ}$ to $+24^{\circ}$ as the frequency range increases from 12 to $17 \mathrm{GHz}$ with broadside at $15.5 \mathrm{GHz}$. The HMSIW LWA with folded ground plane is fabricated and its performance is experimentally measured showing the close agreement between the simulation and the measured results.
\end{abstract}

\section{Keywords}

Miniaturization, folded ground plane, half mode substrate integrated waveguide, broadside gain enhancement, leaky wave antenna

\section{Introduction}

Microwave and millimeter wave systems are widely designed on rectangular waveguides due to their high quality factor and high power handling capacities. However, with the development in satellite communications, antennas with compact size, low profile, high gain, specific radiation patterns and easy integration with planar circuits are more favorable. As a solution to this problem, substrate integrated waveguide (SIW) is being preferred which is a planar waveguide technology suitable for millimeterwave applications because of its ease to manufacture, low cost, small size, low loss, and easy integration with planar circuits [1].

For the purpose of miniaturization, half mode substrate integrated waveguide (HMSIW) on the transverse side was proposed while maintaining the fabrication complexity at the same level [2]. Since its introduction, it has gained enormous interests particularly in the antenna field due to its open geometry. The size of the HMSIW is almost half compared to SIW while maintaining all the advantages of the SIW. The HMSIW is considered as a variant of SIW. The different variations of HMSIW are also available in the literature like truncated HMSIW [3], truncated HMSIW with infinite ground planes [4] (baffles) and the variation of SIW with longitudinal slot closed to one via wall. The variation with longitudinal slot provides extra degrees of freedom to control the leakage of the structure [5]. The propagation constant for HMSIW can be calculated using equivalent model of HMSIW proposed in [6]. Based on the phase constant $\beta$ of the HMSIW, it can operate either in fast wave region $\left(\beta \leq K_{0}\right)$ and slow wave region $\left(\beta>K_{0}\right)$.

The major problem in the conventional periodic LWA is open stop-band (OSB) in the scanning frequency range [7]. The OSB occurs because the reflected waves of each unit cell are in phase at the frequency of broadside radiation. With the advent of metamaterials, leaky wave antennas (LWA) have regained interest because of their backward to forward beam scanning capabilities through broadside [8]. In CRLH LWA (unit cell length, $P<\lambda_{\mathrm{g}} / 4$ ), OSB is suppressed by achieving the balance condition. Various structures of composite right/left handed (CRLH) LWAs on the SIW technology have been proposed [9-12]. In periodic SIW LWAs $\left(P \sim \lambda_{\mathrm{g}}\right)$, the problem of OSB is solved by mainly three techniques, namely, reflection cancellation [13], impedance matching [14] asymmetric technique [15], [16]. However, the frequency-scanning capability of SIW based LWAs is not suitable for more common fixed-frequency applications because of its closed geometry. However, on the other side, the tuning elements can be loaded very easily on the open side of the HMSIW that will result in the electronically scanned LWA [17]. Therefore, HMSIWs have become popular in the design of LWAs over the past years.

In [18], a novel HMSIW based LWA is proposed with quasi-directional radiation patterns. A circularly po- 
larized CRLH based HMSIW LWA with interdigital slots is proposed with OSB suppression in [19]. Two half-mode structures are combined for high gain and a meandered line is inserted between the two elements for increasing the scanning rate sensitivity of the whole LWA [20]. A folded ground plane technique is applied for gain enhancement and further miniaturization in CRLH based HMSIW LWA [21]. The combination of transverse and longitudinal slots as the radiating elements is used for OSB suppression in HMSIW LWA [22]. In [23], a compact CRLH based HMSIW LWA with spiral slots for gain enhancement and radiation efficiency improvement is presented. The main idea is similar to the previously developed HMSIW P-LWA but with the use of folded ground plane, the gain is enhanced by $\sim 2 \mathrm{dBi}$ with OSB suppression. The folded ground plane technique is applied for the CRLH HMSIW LWA [21] but it is not capable of continuous beam scanning through broadside while in the presented HMSIW LWA the continuous beam scanning is obtained.

In this paper, a new periodic LWA based on the HMSIW for Ku-band applications is presented for OSB suppression and miniaturization on the transverse side. Two designs of presented HMSIW LWA with folded and unfolded ground plane are also compared and concluded. The folded configuration of HMSIW LWA is capable of continuous beam steering from $-40^{\circ}$ to $+24^{\circ}$ with broadside gain of $\sim 12 \mathrm{dBi}$.

This paper is organized as follows: The unit cell is analyzed for folded configuration with respect to their dispersion characteristics. The LWAs are designed with folded and unfolded ground planes and are compared in the second section. The experimental results confirm the continuous beam scanning characteristics of presented HMSIW LWA with good impedance matching characteristics and are discussed in the third section and finally the conclusion is drawn in the last section.

\section{Antenna Designing and Analysis}

The unit cell design of the proposed HMSIW LWA with folded ground is shown in Fig. 1(a). The complete LWA designs of folded and unfolded ground are shown in Fig. 1(b), (c). The proposed structures are designed using RT/Duroid 5880 substrate with dielectric constant $\varepsilon_{\mathrm{r}}=2.2$ and height of $0.787 \mathrm{~mm}$ and loss tangent $\tan \delta=0.0009$. The unit cell of the SIW LWA proposed in [16] is converted into HMSIW LWA unit cell by bisecting it through the central line of symmetry. The width for the HMSIW is chosen according to the equations in [6]. The parameters $D, S, W_{\text {eff }}$ denote via diameter, via period and HMSIW effective width, respectively.

The unit cell of the HMSIW LWA is studied and the period $P$ is taken approximately equal to the guided wavelength $\lambda_{\mathrm{g}}$. The cross slot used in the design consists of longitudinal and transversal components for achieving continuous beam scanning. Initially the slots are designed

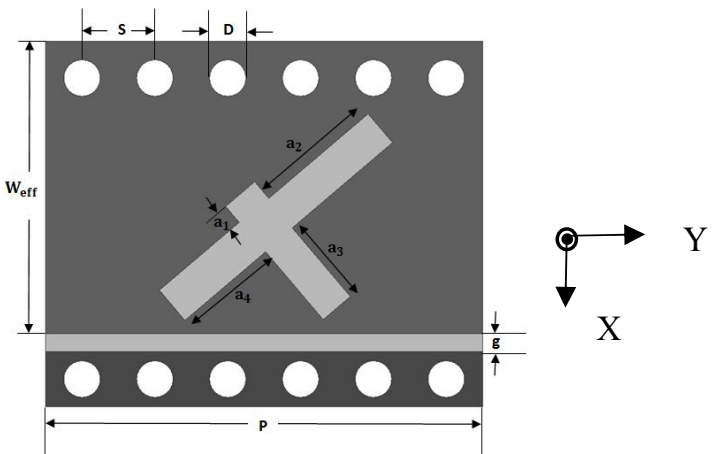

(a)

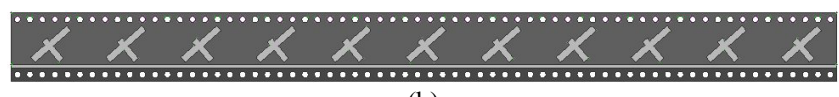

(b)

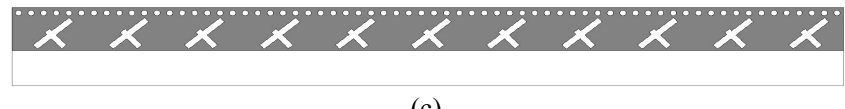

(c)

Fig. 1. (a) Unit cell design with folded ground. (b) HMSIW LWA with folded ground. (c) HMSIW LWA with unfolded ground.

\begin{tabular}{|c|c|}
\hline Parameters & Values (mm) \\
\hline$W_{\text {eff }}$ & 8.52 \\
\hline$D$ & 1 \\
\hline$S$ & 2 \\
\hline$g$ & 0.5238 \\
\hline$a_{1}$ & 1.11 \\
\hline$a_{2}$ & 4.15 \\
\hline$a_{3}$ & 2.99 \\
\hline$a_{4}$ & 3.39 \\
\hline$P$ & 12 \\
\hline$W_{\mathrm{f}}$ & 10.5 \\
\hline$W_{\mathrm{uf}}$ & 14.5 \\
\hline$L$ & 132 \\
\hline
\end{tabular}

Tab. 1. Design parameters of unit cell with folded ground configuration.

according to our broadside frequency and their lengths are taken as $\lambda_{b} / 4$ and $\lambda_{b} / 2$ for transverse and longitudinal direction respectively, and width of the slot is taken as $\sim \lambda_{b} / 20$ where $\lambda_{\mathrm{b}}$ is the wavelength at broadside frequency. The width of the slots is taken as approximately $1 \mathrm{~mm}$. The slot parameters $\left(a_{1}-a_{4}\right)$ are optimized to achieve continuous beam scanning and for the maximum radiation. For the folded ground design of proposed HMSIW LWA, another via-wall covered by a strip on the top is placed beside the open boundary of the HMSIW with a small gap $g$. This via-wall is used to reduce the energy leakage from the open boundary and increases the gain at broadside. It can be viewed as folded ground which helps in further miniaturization in the transverse side [21]. The optimized parameters for the unit cell are shown in Tab. 1.

The OSB suppression in the unit cell can be explained with the help of unit cell's dispersion graph. Attenuation constant, $\alpha_{\mathrm{eff}} P$ and phase constant, $\beta_{\mathrm{eff}} P$ are calculated 
using the formula mentioned in [14]. Figure 2 shows the dispersion graph for a unit cell consisting of the cross slot. The dispersion graph of the proposed unit cell shows that $\alpha_{\text {eff }} P$ is almost zero in operating band and $\beta_{\text {eff }}$ is zero at single frequency unlike at a band of frequency which confirms the OSB suppression for HMSIW LWA unit cell. Therefore, unit cell with longitudinal slot and transversal slots can scan seamlessly from backward to forward through broadside. Decreasing and increasing nature of the phase constant shows the backward and forward frequency scanning ranges. The broadside or transition point is around $15.5 \mathrm{GHz}$.

The real and imaginary parts of the Bloch impedance curve of the HMSIW periodic LWA with both folded and unfolded configurations consisting of 11 unit cells are shown in Fig. 3. These curves are compared with the input impedance for matching purpose. From Bloch impedance curve it is clear that for a folded ground plane design there is only a slight variation of real part of Bloch impedance around the broadside compared to the unfolded ground plane design. Therefore it is anticipated that the gain of the folded design will be more at broadside. The simulated gain patterns for the folded and unfolded configurations are shown in Fig. 5. It is clearly depicted in the figure that broadside gain is enhanced by $\sim 2 \mathrm{dBi}$ at the broadside for the folded ground plane design. The Bloch impedance curve rotates around the input impedance confirming impedance matching for the LWA.

The surface current at $15.5 \mathrm{GHz}$ is plotted at the unit cell to understand the polarization behavior of the proposed LWA as shown in Fig. 4. The surface current distributions are cancelled out at $90^{\circ}$ and $180^{\circ}$ phase difference. From these figures, one can observe that the antenna possess the elliptical polarization which is inherent due to the presence of series and shunt radiating elements [24]. Asymmetry of the cross slots can be controlled for making it a circular polarization.

In order to complete our understanding on the OSB, the influence of different geometrical variations of the design parameters $\left(a_{1}, a_{2}, a_{3}\right.$ and $\left.a_{4}\right)$ on the behavior of the

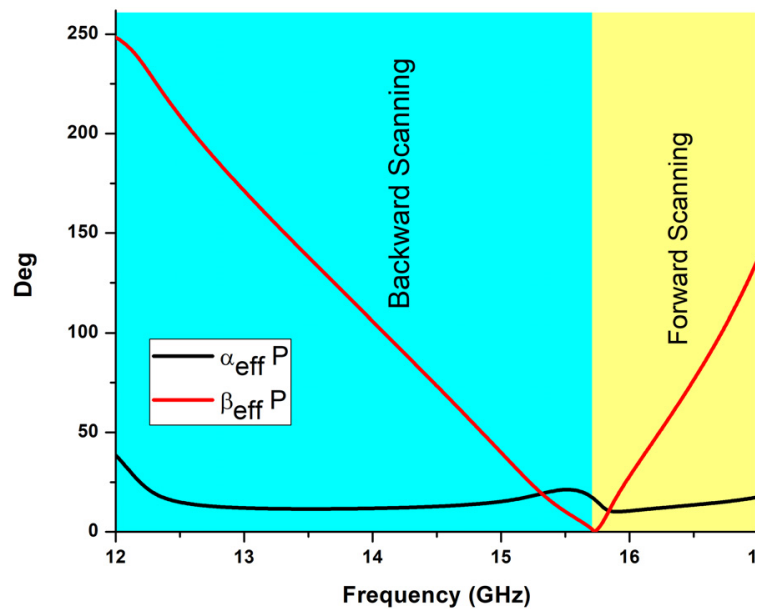

Fig. 2. Normalized dispersion diagram of unit cell with folded ground plane.

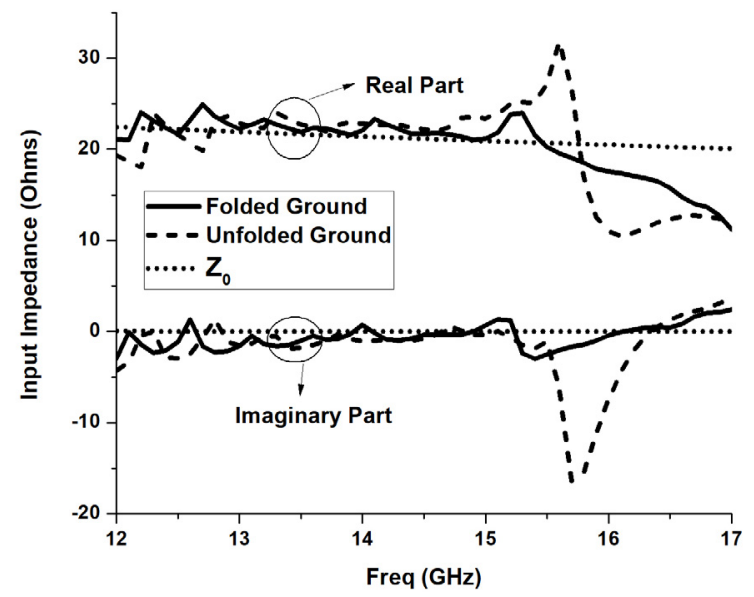

Fig. 3. Bloch impedance of HMSIW LWA with folded and unfolded ground plane designs.

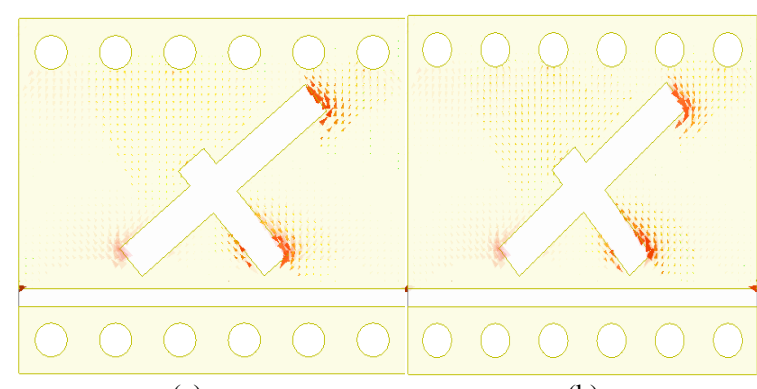

(a)

(b)

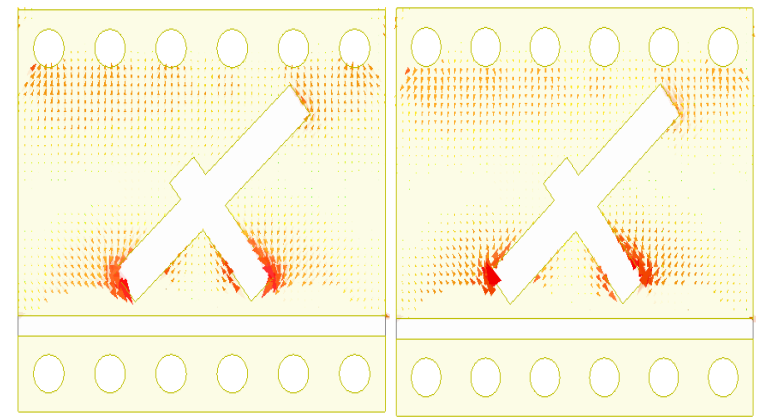

(c)

(d)

Fig. 4. Surface current distibutions $(15.5 \mathrm{GHz})$ on the unit cell at phase of (a) $0^{\circ}$, (b) $270^{\circ}$, (c) $90^{\circ}$, (d) $180^{\circ}$.

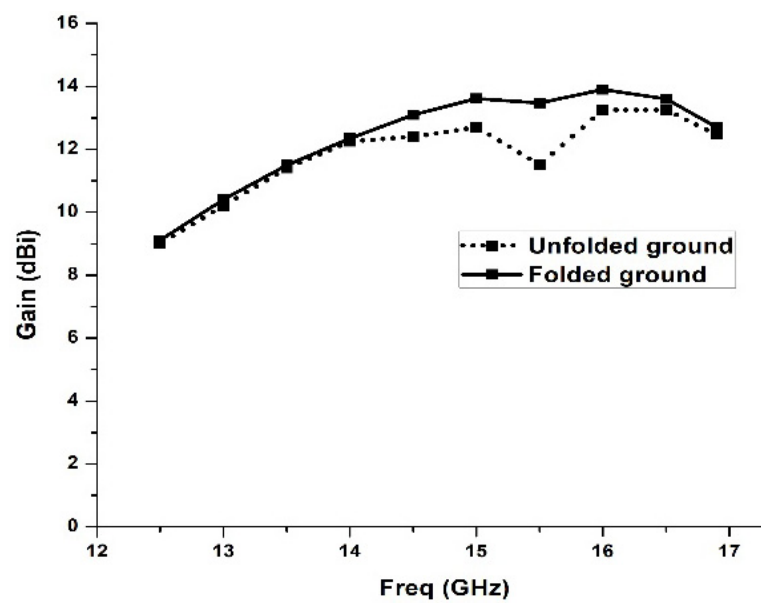

Fig. 5. Gain comparison for folded and unfolded ground plane designs of HMSIW LWA. 


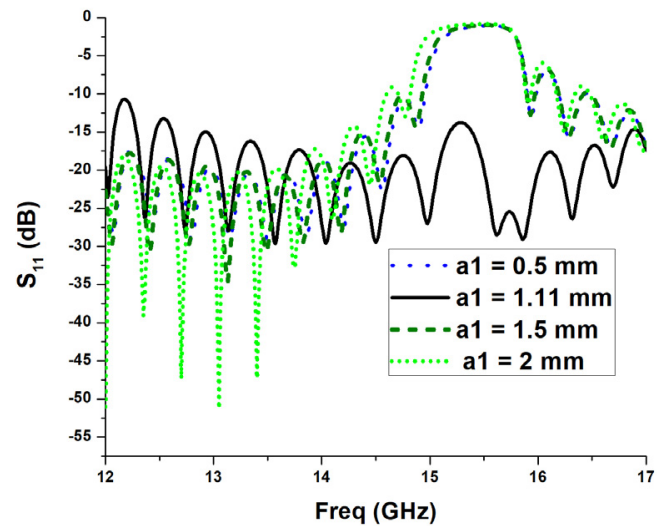

(a)

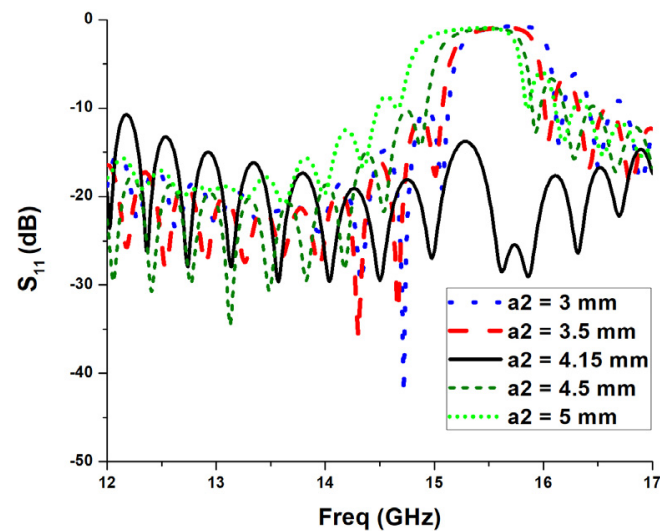

(b)

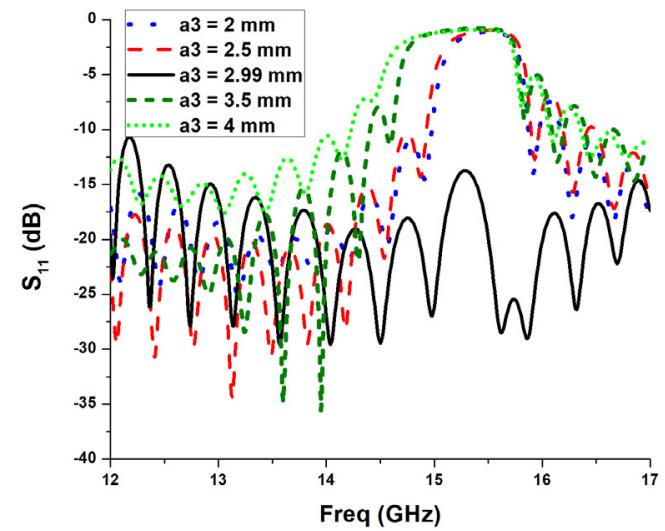

(c)

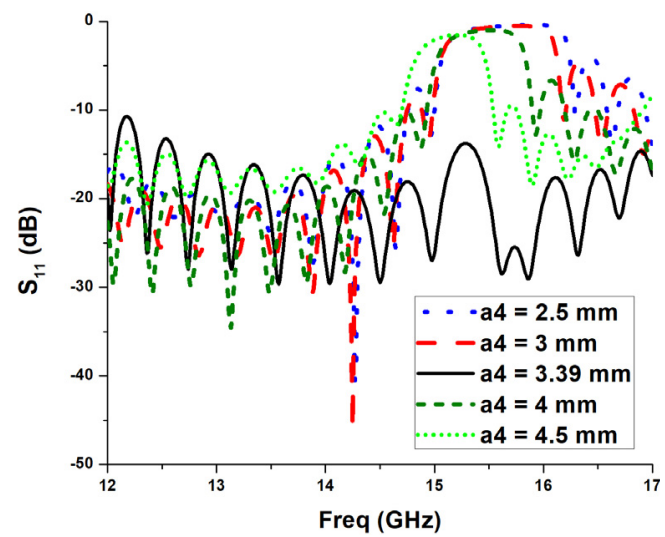

(d)

Fig. 6. OSB parametric study of the folded design by varying parameters (a) $a_{1}$, (b) $a_{2}$, (c) $a_{3}$ (d) $a_{4}$. folded design of the periodic LWA is studied using full wave simulation with Ansys HFSS software package. All the parameters are very crucial in suppression the OSB. The reflection coefficient $\left(\mathrm{S}_{11}\right)$ is displaced by varying $a_{1}-a_{4}$ is shown in Fig. 6(a)-(d). Larger and smaller values of $a_{1}-a_{4}$ introduce the OSB due to the radiating power disturbance of the series and shunt elements.

\section{Experimental Results}

For verification purpose, a HMSIW LWA with folded ground plane design is fabricated and is shown in Fig. 7. This prototype is fed by SMA connectors through microstrip-to-SIW transitions. The tapered sections are used with tapered width equal to $3.4 \mathrm{~mm}$ for broadband impedance matching. The S-parameters are measured using a microwave vector network analyzer (VNA), and the results are depicted in Fig. 8 together with the simulation results. The parameters are all lower than $-10 \mathrm{~dB}$ in the $12 \mathrm{GHz}$ to $17 \mathrm{GHz}$ frequency range. Due to additional reflections caused by the SMA connectors and potential production variations, the measured $S_{11}$ spectrum presents shallower resonance dips compared to the simulated spectrum. Hence, the measured magnitude of the $S_{21}$ prototype's spectral response is also deviating from the corresponding simulated $\mathrm{S}_{21}$ spectrum due to the worsened $\mathrm{S}_{11}$. The fraction of the input power that should go to the output connector can be inferred from the plot of radiation efficiency as shown in Fig. 9. The radiation efficiency is not uniform all over the frequency range and there is little bump at the broadside. The efficiency of the LWA varies from 75 to 95 percentage.

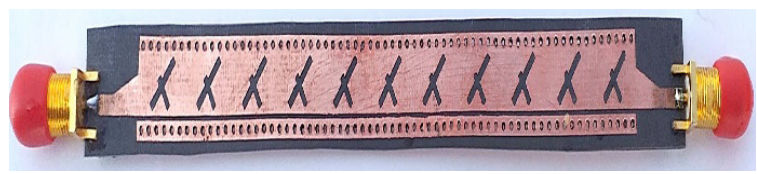

Fig. 7. The fabricated prototype of HMSIW LWA with folded ground plane.

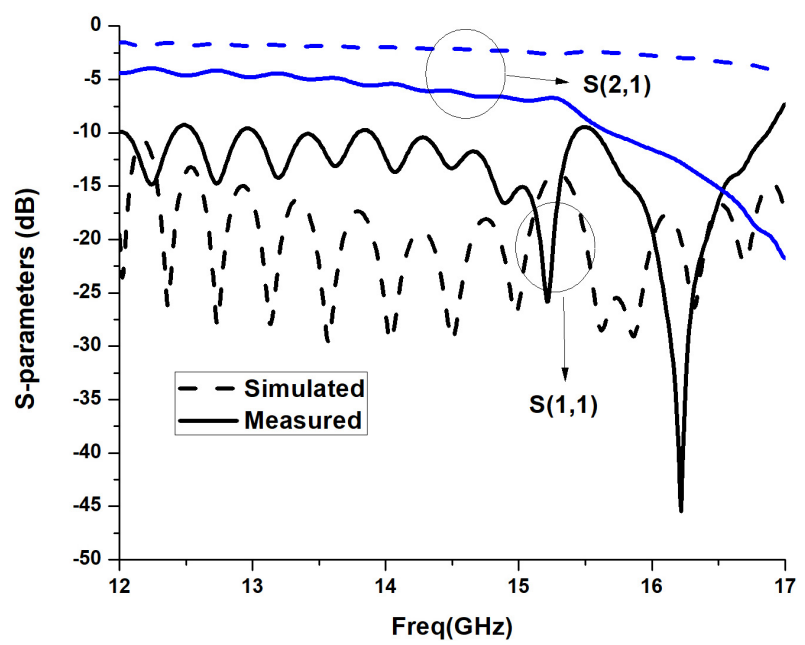

Fig. 8. S-parameters of HMSIW LWA with folded ground plane. 


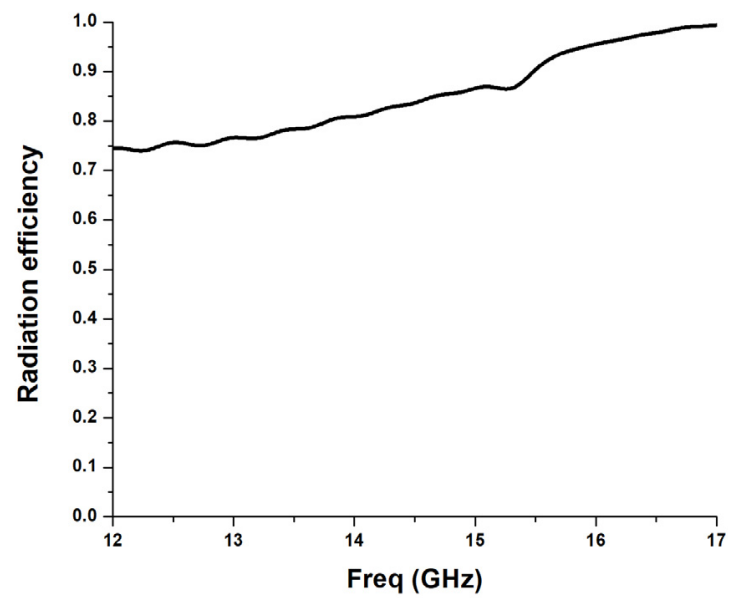

Fig. 9. Radiation efficiency of the LWA.

Figure 10 presents the experimental radiation patterns measured through far-field measurement system in an anechoic chamber. The far-field radiation pattern of this antenna indicates a directional patterns characteristic in $\mathrm{E}$ plane $(\mathrm{Y}-\mathrm{Z})$. Both E-plane and $\mathrm{H}$-plane radiation patterns at $12 \mathrm{GHz}, 15.5 \mathrm{GHz}$ (broadside) and $16.9 \mathrm{GHz}$ are shown in Fig. 10(a), (b). The well agreed measured and simulated results demonstrate that the main radiation beam of the prototype scans from $-40^{\circ}$ at $12 \mathrm{GHz}$ to $+24^{\circ}$ at $16.9 \mathrm{GHz}$ with smooth transition through broadside at $15.5 \mathrm{GHz}$.

The E-and H-plane patterns constitute a frequencydependent scanning, with maximum radiation in the broadside. The measured and simulated gain patterns for folded configuration are shown in Fig. 11. The maximum gain realized for the scanning range for the prototype is $\sim 12 \mathrm{dBi}$. A dip in the gain at broadside is seen which is a result of poor matching at the broadside point. The similar reported works are shown in Tab. 2. The presented HMSIW LWA has unit cell length $P$ approximately equal to the guided wavelength $\lambda_{\mathrm{g}}$ whereas the structures based on CRLH technology have a unit length $P<\lambda_{\mathrm{g}} / 4$, which increases their numerical and fabrication complexity. Thus, the proposed HMSIW LWA is easy to fabricate as compared to other contemporary antennas, which proves its novelty. Also, Table 2 reveals that the proposed antenna is compact as compared to other periodic HMSIW based LWA antennas.

\section{Conclusion}

A miniaturized frequency scanned LWA based on HMSIW for the Ku-band with OSB suppression is proposed. Miniaturization is achieved on the transverse side using HMSIW technology compared to the LWAs based on SIW technology. The unfolded and folded ground configurations are compared and it is concluded that further miniaturization by $4 \mathrm{~mm}$ and gain improvement at broadside of nearly $2 \mathrm{dBi}$ is achieved for folded ground plane design. This folded ground plane design of LWA is capable of scanning the beam from $-40^{\circ}$ to $+24^{\circ}$ with broadside at $15.5 \mathrm{GHz}$ with the maximum gain of $12 \mathrm{dBi}$.

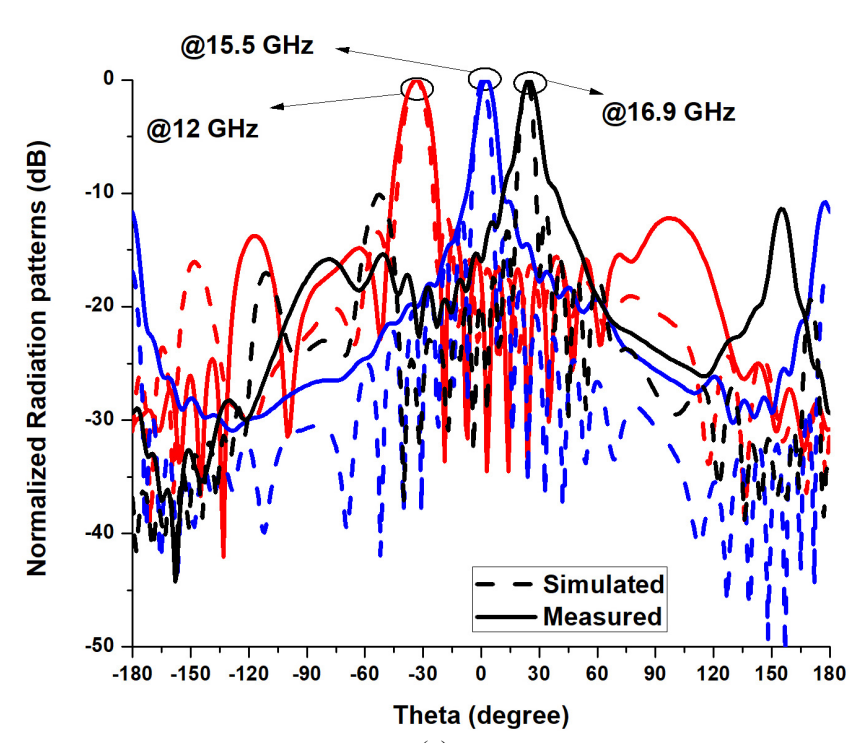

(a)

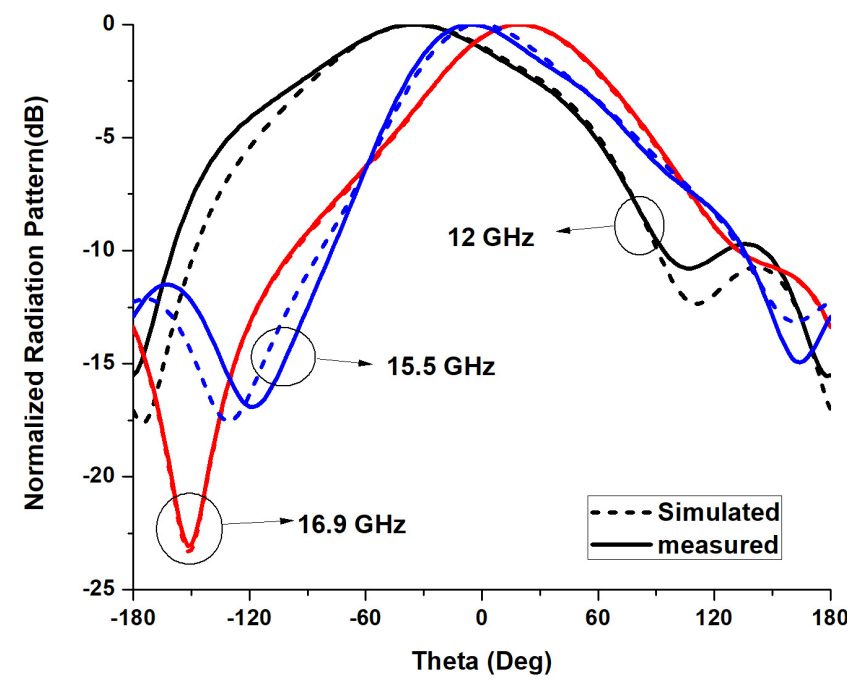

(b)

Fig. 10. (a) Normalized E plane (Y-Z plane) and (b) H-plane (X-Z plane) radiation patterns of HMSIW LWA with folded ground.

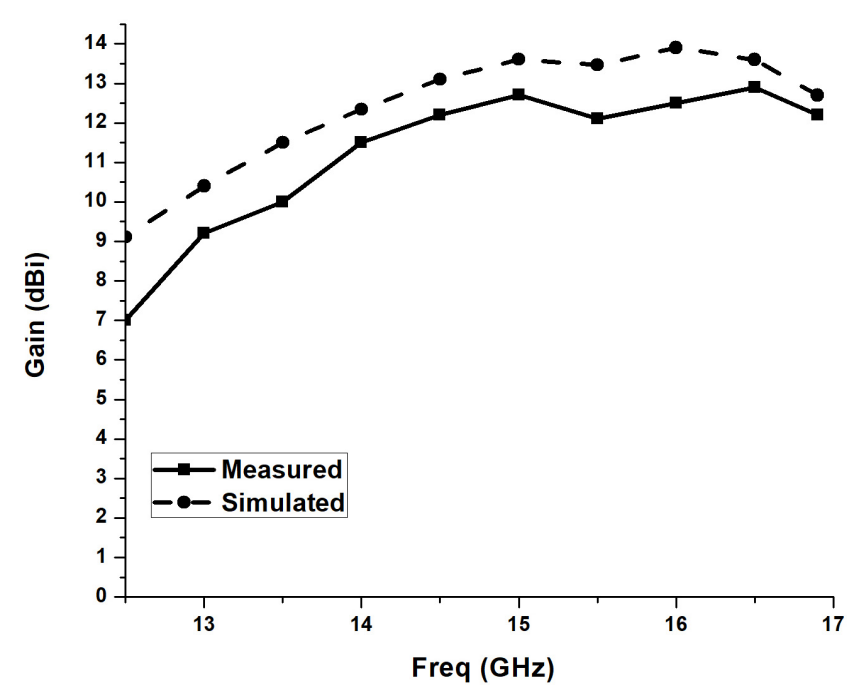

Fig. 11. Simulated and measured gain of HMSIW LWA with folded ground plane. 


\begin{tabular}{|c|c|c|c|c|c|c|c|}
\hline Ref & Antenna type & $\begin{array}{l}\text { Radiator } \\
\text { length }\end{array}$ & $\begin{array}{c}\text { Scanning } \\
\text { freq. range } \\
(\mathbf{G H z})\end{array}$ & $\begin{array}{l}\text { Designing and } \\
\text { fabrication } \\
\text { complexity }\end{array}$ & $\begin{array}{l}\text { Backward to forward } \\
\text { beam scanning }\end{array}$ & Pol & $\begin{array}{l}\text { Peak gain } \\
\quad \text { (dBi) }\end{array}$ \\
\hline $\begin{array}{l}{[19]} \\
2014\end{array}$ & $\begin{array}{l}\text { CRLH HMSIW LWA } \\
\qquad\left(P<<<\lambda_{\mathrm{g}}\right)\end{array}$ & $\sim 6.25 \lambda_{0}$ & 7.4 to 13.5 & Complex & Yes $\left(-70^{\circ}\right.$ to $\left.+70^{\circ}\right)$ & $\mathrm{CP}$ & $\sim 12 \mathrm{dBi}$ \\
\hline $\begin{array}{l}{[21]} \\
2011\end{array}$ & $\begin{array}{l}\text { CRLH HMSIW LWA } \\
\qquad\left(P<<<\lambda_{\mathrm{g}}\right)\end{array}$ & $\sim 5 \lambda_{0}$ & 8.5 to 12 & Complex & No $\left(-35^{\circ}\right.$ to $\left.+37^{\circ}\right)$ & LP & $\sim 10 \mathrm{dBi}$ \\
\hline $\begin{array}{l}{[25]} \\
2018\end{array}$ & $\begin{array}{l}\text { Periodic HMSIW LWA } \\
\qquad\left(P \sim \lambda_{\mathrm{g}}\right)\end{array}$ & $\sim 8 \lambda_{0}$ & 10 to 14 & Simple & Yes $\left(-27^{\circ}\right.$ to $\left.+23^{\circ}\right)$ & LP & $\sim 11.5 \mathrm{dBi}$ \\
\hline $\begin{array}{r}{[23]} \\
2018\end{array}$ & $\begin{array}{l}\text { CRLH HMSIW LWA } \\
\qquad\left(P<<<\lambda_{\mathrm{g}}\right)\end{array}$ & $\sim 4.85 \lambda_{0}$ & 13.5 to 17.8 & Complex & Yes $\left(-66^{\circ}\right.$ to $\left.+20^{\circ}\right)$ & NA & $\sim 16 \mathrm{dBi}$ \\
\hline $\begin{array}{l}{[26]} \\
2015\end{array}$ & $\begin{array}{l}\text { Periodic HMSIW LWA } \\
\qquad\left(P \sim \lambda_{\mathrm{g}}\right)\end{array}$ & $\sim 10 \lambda_{0}$ & 32 to 46 & Simple & No $\left(-44^{\circ}\right.$ to $\left.+77^{\circ}\right)$ & NA & $\sim 13 \mathrm{dBi}$ \\
\hline $\begin{array}{l}\text { This } \\
\text { work }\end{array}$ & $\begin{array}{l}\text { Periodic HMSIW LWA } \\
\qquad\left(P \sim \lambda_{\mathrm{g}}\right)\end{array}$ & $\sim 7.5 \lambda_{0}$ & 12 to 16.9 & Simple & Yes $\left(-40^{\circ}\right.$ to $\left.+24^{\circ}\right)$ & EP & $\sim 12 \mathrm{dBi}$ \\
\hline
\end{tabular}

Tab .2. Comparison with other reported HMSIW LWA design.

\section{References}

[1] DESLANDES, D., WU, K. Integrated microstrip and rectangular waveguide in planar form. IEEE Microwave and Wireless Components Letters, 2001, vol. 11, no. 2, p. 68-70. DOI: $10.1109 / 7260.914305$

[2] HONG, W., LIU, B., WANG, Y., et al, Half mode substrate integrated waveguide: A new guided wave structure for microwave and millimeter wave application. In Proceedings of 31st International Conference on Infrared and Millimeter Waves. Shanghai (China), 2006, p. 18-22. DOI: 10.1109/ICIMW.2006.368427

[3] NGUYEN-TRONG, N., KAUFMANN, T., FUMEAUX, C. A wideband omnidirectional horizontally polarized traveling-wave antenna based on half-mode substrate integrated waveguide. IEEE Antennas and Wireless Propagation Letters, 2013, vol. 12, p. 682-685. DOI: 10.1109/LAWP.2013.2263492

[4] RUMSEY, V. H. Traveling wave slot antennas. Journal of Applied Physics, 1953, vol. 24, no. 11, p. 1358-1365. DOI: $10.1063 / 1.1721178$

[5] NGUYEN-TRONG, N., HALL, L. T., FUMEAUX, C. Variational analysis of substrate-integrated waveguides with longitudinal slot. In Proceedings of International Applied Computational Electromagnetics Society Symposium (ACES). Florence (Italy), 2017, p. 1-2. DOI: 10.23919/ROPACES.2017.7916367

[6] LAI, Q., FUMEAUX, C., HONG, W. et al, Characterization of the propagation properties of the half-mode substrate integrated waveguide. IEEE Transactions on Microwave and Theory Techniques, 2009, vol. 57 no. 8, p. 1996-2004. DOI: 10.1109/TMTT.2009.2025429

[7] WILliaMS, J. T., BACCARELLI, P., PAULOTTO, S. et al. 1-D combline leaky-wave antenna with the open-stopband suppressed: Design considerations and comparisons with measurements. IEEE Transactions on Antennas and Propagation, 2013, vol. 61, no. 9, p. 4484-4492. DOI: 10.1109/TAP.2013.2271234

[8] LIU, L., CALOZ, C., ITOH, T. Dominant mode leaky-wave antenna with backfire-to-endfire scanning capability. Electronics Letters, 2006, vol. 38, no. 23, p. 1414-1416. DOI: 10.1049/el:20020977
[9] NASIMUDDIN, N., CHEN, Z. N., QING, X. Multilayered composite right/left-handed leaky-wave antenna with consistent gain. IEEE Transactions on Antennas and Propagation, 2012, vol. 60 , no. 11, p. 5056-5062. DOI: 10.1109/TAP.2012.2207680

[10] NASIMUDDIN, N., CHEN, Z. N., QING, X. Tapered composite right/left-handed leaky-wave antenna for wideband broadside radiation. Microwave and Optical Technology Letters, 2015, vol. 57, no. 3, p. 624-629. DOI: 10.1002/mop. 28916

[11] NASIMUDDIN, N., CHEN, Z. N., QING, X. Substrate integrated metamaterial-based leaky-wave antenna with improved boresight radiation bandwidth. IEEE Transactions on Antennas and Propagation, 2013, vol. 61, no. 7, p. 3451-3457. DOI: 10.1109/TAP.2013.2256094

[12] AGRAWAL, R., BELWAL, P., GUPTA, S. C. Continuous beam scanning in substrate integrated waveguide leaky wave antenna. Progress in Electromagnetic Research M, 2017, vol. 62, p. 19-28. DOI: 10.2528/PIERM17091104

[13] GUGLIELMI, M., JACKSON, D. R. Broadside radiation from periodic leaky-wave antennas. IEEE Transactions on Antennas and Propagation, 1993. vol. 41, no. 1, p. 31-37. DOI: $10.1109 / 8.210112$

[14] LYU, Y., LIU, X., WANG, P. Y., et al. Leaky-wave antennas based on non-cutoff substrate integrated waveguide supporting beam scanning from backward to forward. IEEE Transactions on Antennas and Propagation, 2016, vol. 64, no. 6, p. 2155-2164. DOI: 10.1109/TAP.2016.2550054

[15] OTTO, S., AL-BASSAM, A., RENNING, A., et.al. Transversal asymmetry in periodic leaky-wave antennas for Bloch impedance and radiation efficiency equalization through broadside. IEEE Transactions on Antennas and Propagation, 2014, vol. 62, no. 10, p. 5037-5054. DOI: 10.1109/TAP.2014.2343621

[16] AGRAWAL, R., BELWAL, P., GUPTA, S. Asymmetric substrate integrated waveguide leaky wave antenna with open stop band suppression and radiation efficiency equalization through broadside. Radioengineering, 2018, vol. 27, no. 2, p. 409-416. DOI: $10.13164 /$ re.2018.0409

[17] SUNTIVES, A., HUM, S. V. A fixed-frequency beam-steerable half-mode substrate integrated waveguide leaky-wave antenna. IEEE Transactions on Antennas and Propagation, 2012, vol. 60, no. 5, p. 2540-2544. DOI: 10.1109/TAP.2012.2189726 
[18] XU, J., HONG, W., TANG, H. et al. Half-mode substrate integrated waveguide (HMSIW) leaky-wave antenna for millimeter-wave applications. IEEE Antennas and Wireless Propagation Letters, 2008, vol. 7, p. 85-88. DOI: 10.1109/LAWP.2008.919353

[19] POURGHORBAN SAGHATI, A., MIRSALEHI, M. M., NESHATI, M. H. A HMSIW circularly polarized leaky-wave antenna with backward, broadside, and forward radiation. IEEE Antennas Wireless Propagation Letters, 2014, vol. 13, p. 451-454. DOI: 10.1109/LAWP.2014.2309557

[20] ZHANG, H., JIAO, Y. C., ZHAO, G., et al. Half-mode substrate integrated waveguide-based leaky-wave antenna loaded with meandered lines. Electronics. Letters, 2017, vol. 53, no. 17, p. 1172-1174. DOI: 10.1049/el.2017.2251

[21] DONG, Y., ITOH, T. Composite right / left-handed substrate integrated waveguide and half mode substrate integrated waveguide leaky-wave structures. IEEE Transactions on Antennas and Propagation, 2011, vol. 59, no. 3, p. 767-775. DOI: 10.1109/TAP.2010.2103025

[22] PAULOTTO, S., BACCARELLI, P., FREZZA, F., et al. Full-wave modal dispersion analysis and broadside optimization for a class of microstrip. IEEE Transactions on Microwave Theory and Technique, 2008, vol. 56, no. 12, p. 2826-2837. DOI: 10.1109/TMTT.2008.2007333

[23] SARKAR, A., ADHIKARY, M., SHARMA, A., et al. Composite right-/left-handed based compact and high gain leaky-wave antenna using complementary spiral resonator on HMSIW for $\mathrm{Ku}$ band applications. IET Microwaves and Antennas Propagation, 2018, vol. 12, no. 8, p. 1310-1315. DOI: 10.1049/iet-map.2017.0478

[24] OTTO, S., CHEN, Z., AL-BASSAM, A., et al. Circular polarization of periodic leaky-wave antennas with axial asymmetry: Theoretical proof and experimental demonstration. IEEE Transactions on Antennas and Propagation, 2014, vol. 62, no. 4, p. 1817-1829. DOI: 10.1109/TAP.2013.2297169

[25] LIU, L., GU, X., ZHU, L., et al. A novel half mode substrate integrated waveguide leaky-wave antenna with continuous forward-to-backward beam scanning functionality. International Journal of RF \& Microwave Computer-aided Engineering, 2018, vol. 28 , no. 9 , p. 1-6. DOI: $10.1002 /$ mmce. 21559

[26] MUJUMDAR, M., ALPHONES, A., NASIMUDDIN. Compact leaky wave antenna with periodical slots on half mode substrate integrated waveguide. In Proceedings of IEEE International
Symposium on Antennas and Propagation \& USNC/URSI National Radio Science Meeting. Vancouver (Canada), 2015, p. 1740-1741. DOI: 10.1109/APS.2015.7305259

\section{About the Authors ...}

Rahul AGRAWAL (corresponding author) was born in Guna (M.P). He received his B.Tech (Electr. Comm. Eng.) from RGPV, Bhopal and his M.Tech from DIT University, Dehradun. Currently he is a working as a Senior Research Fellow for DRDO funded project in DIT University, Dehradun. His research interests include: transmission lines (CRLH), SIW technology, leaky wave antenna (LWA), miniaturization in LWA, dispersion enhancement in LWAs, diplexers and triplexers.

Pravesh BELWAL was born in Chamba (Uttarakhand). He received his B.Tech (Electr. Comm. Eng.) from UPTU, Lucknow and his M.Tech from DIT University, Dehradun. Currently he is a Research Fellow in DIT University, Dehradun. His research interests include: half mode SIW, electronic beam scanning of LWA.

Suresh GUPTA was born in Delhi. He received his M.Tech from IIT Bombay and PhD from IIT Roorkee in 1971. After putting a service of 34 years in IIT Roorkee, presently he is working as a Prof. and Dean (PG) at DIT University, Dehradun. He has supervised number of M. tech and $\mathrm{PhD}$ students and published an around 150 research papers in various journals and international conferences in the area of antenna and microwave engineering. He has also supervised the DRDO project on Development of Stealth materials and technology in IIT Roorkee. Currently, he is supervising the DRDO project at DIT University as principal investigator in the advance leaky wave antenna field. 